Check for updates

Cite this: RSC Adv., 2018, 8, 14377

Received 8th January 2018 Accepted 22nd March 2018

DOI: $10.1039 / c 8 r a 00205 c$

rsc.li/rsc-advances

\section{Characterization of aluminum, aluminum oxide and titanium dioxide nanomaterials using a combination of methods for particle surface and size analysis $\dagger$}

\author{
B. Krause, (D) ${ }^{* a}$ T. Meyer, ${ }^{b}$ H. Sieg, ${ }^{c}$ C. Kästner, (D) ${ }^{d}$ P. Reichardt, ${ }^{a}$ J. Tentschert, ${ }^{a}$ \\ H. Jungnickel, ${ }^{a}$ I. Estrela-Lopis, ${ }^{b}$ A. Burel, ${ }^{e}$ S. Chevance, (DD ${ }^{f}$ F. Gauffre, (D) ${ }^{f}$ P. Jalili, ${ }^{g}$ \\ J. Meijer, ${ }^{h}$ L. Böhmert, ${ }^{c}$ A. Braeuning, ${ }^{c}$ A. F. Thünemann, (D) ${ }^{d}$ F. Emmerling, (D) ${ }^{i}$ \\ V. Fessard, ${ }^{\mathrm{g}}$ P. Laux, (D) ${ }^{\text {a }}$ A. Lampen ${ }^{\mathrm{c}}$ and A. Luch (D) ${ }^{\text {a }}$
}

The application of appropriate analytical techniques is essential for nanomaterial (NM) characterization. In this study, we compared different analytical techniques for NM analysis. Regarding possible adverse health effects, ionic and particulate NM effects have to be taken into account. As NMs behave quite differently in physiological media, special attention was paid to techniques which are able to determine the biosolubility and complexation behavior of NMs. Representative NMs of similar size were selected: aluminum $\left(\mathrm{Al}^{\circ}\right)$ and aluminum oxide $\left(\mathrm{Al}_{2} \mathrm{O}_{3}\right)$, to compare the behavior of metal and metal oxides. In addition, titanium dioxide $\left(\mathrm{TiO}_{2}\right)$ was investigated. Characterization techniques such as dynamic light scattering (DLS) and nanoparticle tracking analysis (NTA) were evaluated with respect to their suitability for fast characterization of nanoparticle dispersions regarding a particle's hydrodynamic diameter and size distribution. By application of inductively coupled plasma mass spectrometry in the single particle mode (SP-ICP-MS), individual nanoparticles were quantified and characterized regarding their size. SP-ICP-MS measurements were correlated with the information gained using other characterization techniques, i.e. transmission electron microscopy (TEM) and small angle X-ray scattering (SAXS). The particle surface as an important descriptor of NMs was analyzed by X-ray diffraction (XRD). NM impurities and their colocalization with biomolecules were determined by ion beam microscopy (IBM) and confocal Raman microscopy (CRM). We conclude advantages and disadvantages of the different techniques applied and suggest options for their complementation. Thus, this paper may serve as a practical guide to particle characterization techniques.

\section{Introduction}

The specific properties of NMs depend on their physicochemical characteristics. Optical properties build upon the size, the shape and the surface structure, ${ }^{1,2}$ while higher reactivity, for example, may result from a high surface area, ${ }^{3,4}$ specific surface coatings ${ }^{5}$ or a surface charge. ${ }^{6-8}$ An important factor for increasing their activity is the self-assembly of NMs. Here, NMs associate via noncovalent interactions resulting in organized structures of higherorder. Different applications based on advanced functions were
${ }^{a}$ German Federal Institute for Risk Assessment (BfR), Department of Chemical and Product Safety, Max-Dohrn-Straße 8-10, 10589 Berlin, Germany. E-mail: benjamin-christoph.krause@bfr.bund.de

${ }^{b}$ Institute of Medical Physics and Biophysics, University of Leipzig, Härtelstrasse 1618, 04275 Leipzig, Germany

${ }^{c}$ German Federal Institute for Risk Assessment (BfR), Department of Food Safety, Max-Dohrn-Straße 8-10, 10589 Berlin, Germany

${ }^{d}$ Federal Institute for Materials Research and Testing (BAM), Unter den Eichen 87, 12205 Berlin, Germany

${ }^{e}$ MRIC TEM BIOSIT, Université de Rennes 1, 2 av pro Leon Bernard, France

${ }^{f}$ Univ Rennes, CNRS, ISCR UMR6226, F-35000 Rennes, France

${ }^{g}$ ANSES, French Agency for Food, Environmental and Occupational Health and Safety, Fougères Laboratory, 10B rue Claude Bourgelat, 35306, Fougères Cedex, France
${ }^{h}$ Felix Bloch Institute for Solid State Physics, Faculty of Physics and Geosciences, Division of Nuclear Solid State Physics, University of Leipzig, Linnéstraße 5, 04103 Leipzig, Germany

${ }^{i}$ Federal Institute for Materials Research and Testing (BAM), Richard-WillstätterStraße 11, 12489 Berlin, Germany

$\dagger$ Electronic supplementary information (ESI) available: NTA size distributions for $\mathrm{Al}^{0}, \mathrm{Al}_{2} \mathrm{O}_{3}, \mathrm{NM103}$, NM104, DLS number-based distribution for $\mathrm{Al}^{0}, \mathrm{Al}_{2} \mathrm{O}_{3}$, NM103, NM104, TEM measurement of $\mathrm{TiO}_{2}$ NMs in DMEM, SAXS data for $\mathrm{Al}^{0}$, $\mathrm{Al}_{2} \mathrm{O}_{3}$ and $\mathrm{AlCl}_{3}$ in BSA and DMEM after 24 and $48 \mathrm{~h}$, impurities of used NMs determined by IBM, aluminium aqua complexes at different $\mathrm{pH}$ values, CRM surface investigations, colocalization pattern by IBM for $\mathrm{Al}_{2} \mathrm{O}_{3}, \mathrm{CRM}$ spectra displaying protein modifications, ToF-SIMS measurements of $\mathrm{Al}$ and $\mathrm{Al}_{2} \mathrm{O}_{3}$ NMs in DMEM, ToF-SIMS measurements of $\mathrm{TiO}_{2}$ NMs in DMEM. See DOI: $10.1039 / \mathrm{c} 8 \mathrm{ra00205c}$ 
reported, for example formation of mesoporous $\mathrm{TiO}_{2}$ mediated by ionic liquids for solar cell conversion, catalysis or electronic devices. ${ }^{9-11}$ Another application is the self-assembly of biomolecules, like lipids and proteins, mediating inner-particle mesoporosity in a macroporous $\mathrm{TiO}_{2}$ structure. ${ }^{12}$

$\mathrm{TiO}_{2} \mathrm{NMs}$ are classified as granular biodurable particles (GBPs) of low toxicity. ${ }^{13}$ They occur in the form of anatase or rutile as well as in mixtures thereof. While significant accumulation was shown in the liver of rats in the case of orally administered $\mathrm{TiO}_{2} \mathrm{NMs}^{,{ }^{14}}$ this was different in studies with $\mathrm{Al}^{0}$ NMs in mice, in which predominant accumulation in the brain, thymus and lung was revealed. ${ }^{15}$ Characterization is important for both in vitro and in vivo studies. Currently, the human health risk assessment of NMs is mainly based on in vivo experiments in rodents. ${ }^{16,17}$ However, due to the high number of new NMs, ${ }^{18}$ it is not ethical or feasible to conduct such studies for each individual NM. On the other hand, in vitro systems proved useful, e.g. to generate high throughput data. ${ }^{19}$ Extrapolation to the in vivo situation remains limited, in particular due to the insufficient comparability of applied dose and particle biotransformation..$^{\mathbf{2 0 2 1}}$ An accurate characterization of NMs in in vitro systems by the application of up-to-date analytical methods may therefore help to establish reliable methods for determination of nanomaterial uptake and translocation as key parameters that affect NM-related toxicity. Such an approach would therefore help to reduce the number of materials that need to be subjected to animal testing. We investigated rather soluble $\mathrm{Al}^{0}$ and rather insoluble $\mathrm{Al}_{2} \mathrm{O}_{3}$ and $\mathrm{TiO}_{2} \mathrm{NMs}$ (Fig. 1).

This classification is important for NMs because even the same chemical composition can exhibit differences in physicochemical properties. Compared to bulk material, variations are much higher for NMs. ${ }^{22,23}$

For the characterization of test materials, we applied a combination of techniques based on different measuring principles. With DLS as intensity-weighted method, we assessed the hydrodynamic diameter and the polydispersity of the materials in aqueous suspensions and cell culture media (CCM). To validate the results, the more reliable, number-based approach of NTA was applied. The two methods, DLS and NTA, were performed in two different laboratories, allowing for a direct comparison of the results achieved. For particle surface

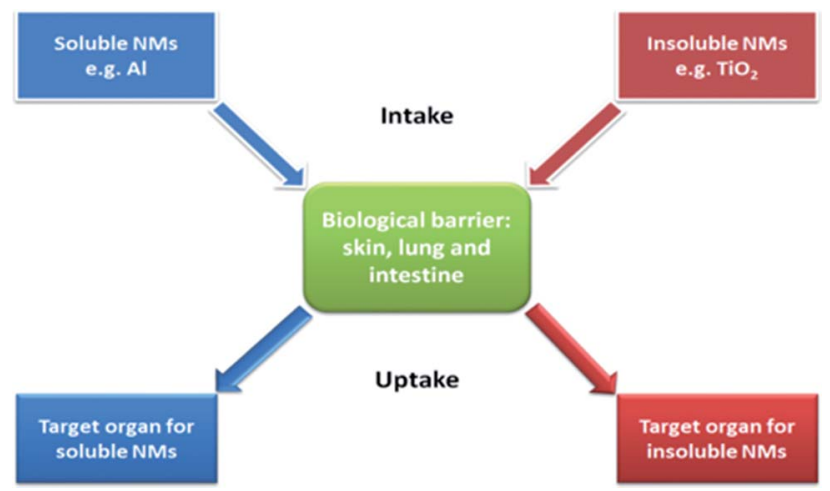

Fig. 1 Hypothesis of different behavior of soluble and insoluble NMs after uptake. investigation, $\mathrm{XRD}$ was used to test whether the aluminum was already oxidized. The core diameter of $\mathrm{Al}^{0}, \mathrm{Al}_{2} \mathrm{O}_{3}$ and both $\mathrm{TiO}_{2}$ NMs was measured by SP-ICP-MS. These results were compared to TEM measurements. As a further technique for estimation of the core diameter, SAXS was applied. Additionally, IBM and CRM were performed to analyze the interaction of NMs with biomolecules as well as to quantify impurities in the NM composition. ToF-SIMS is capable of visualizing the formation of complexes out of $\mathrm{Al}^{\mathrm{O}}$ and $\mathrm{Al}_{2} \mathrm{O}_{3} \mathrm{NMs}$ with components of the environmental media. This allows investigation of the behavior of NMs within physiological fluids such as CCM.

With respect to uptake, the dissolution of NMs in different media is of high importance. For example, during an artificial digestion procedure, different $\mathrm{pH}$ values, as well as proteins, enzymes and other compounds, mimic the oral uptake route for NMs. For $\mathrm{Al}^{0}$ and $\mathrm{Al}_{2} \mathrm{O}_{3} \mathrm{NMs}$, an increased dissolution within the gastric environment was noticed. ${ }^{24}$ However, to properly interpret and compare the results, precise knowledge of the properties of the starting materials and of their state in CCM is required. Although there are a lot of studies dealing with silver and copper-containing NMs and their dissolution behavior in biological media, ${ }^{25-27}$ to our knowledge, no study accounts for $\mathrm{Al}^{0}$ NMs. Furthermore, the dissolution behavior of aluminumcontaining nanomaterials may be very different since aluminum ions already have a different complexation behavior compared to silver or copper ions. By means of the methods described earlier (Fig. 2), we were able to obtain valuable information to hypothesize the behavior of NMs in biological media and to extrapolate to the in vivo situation. With these assumptions, it is much easier to understand and explain future data resulting from more complex scenarios.

\section{Experimental}

\section{Materials and methods}

$\mathrm{Al}^{0} \mathrm{NMs}$ (mean diameter $18 \mathrm{~nm}$ (TEM), 99.9\%) and $\mathrm{Al}_{2} \mathrm{O}_{3} \mathrm{NMs}$ (mean diameter $20 \mathrm{~nm}$ (TEM), 99+\%) were purchased from IoLiTec Ionic Liquids Technologies GmbH, Heilbronn, Germany. $\mathrm{TiO}_{2}$ NMs (NM103 and NM104, mean diameter $25 \mathrm{~nm}$ (TEM)) were purchased from JRC Joint Research Centre, Ispra, Italy. Bovine serum albumin (BSA) was bought from Sigma Aldrich. CCM (DMEM, high glucose $\left(4.5 \mathrm{~g} \mathrm{l}^{-1}\right)$, with sodium pyruvate; with L-glutamine; with $1 \%$ penicillin/streptomycin (P/ S)) and fetal bovine serum were purchased from PAA Laboratories GmbH, Paching, Austria. All other chemicals used in this study were reagent grade.

\section{Sample preparation}

NM dispersions were prepared following the NanoGenoTOX dispersion protocol "Final protocol for producing suitable manufactured NMs exposure media" (October 2011). ${ }^{28}$

For cell culture experiments, stock dispersions of NMs were diluted in DMEM with $10 \%$ fetal calf serum (FCS) to either 10 or $100 \mu \mathrm{g} \mathrm{ml} \mathrm{m}^{-1}$.

For ion release testing, stock dispersions were diluted in $0.05 \%$ BSA to 100 and $10 \mu \mathrm{g} \mathrm{ml}^{-1}$ to reflect a high and a low 
concentration used in cell culture experiments. $1 \mathrm{ml}$ was taken and centrifuged at $16000 \times g$ for $1 \mathrm{~h}$ (Hettich Zentrifuge Mikro 220R). $500 \mu \mathrm{l}$ of the supernatant were taken, $750 \mu \mathrm{l}$ of $\mathrm{HNO}_{3}$ $(69 \%)$ were added and Millipore water was used to fill up to $15 \mathrm{ml}$.

For IBM and CRM, NMs were centrifuged at $8000 \times g$ for $10 \mathrm{~min}$, supernatant was taken away, $\mathrm{mpH}_{2} \mathrm{O}$ was added and the sample was vortexed. The procedure was repeated 3 times. Finally, a small drop of the sample was given on polypropylene foil for IBM and on quartz glass for CRM. The dry samples were measured.

\section{Dynamic light scattering measurements}

The distributions of the hydrodynamic diameters of the NMs were determined using a Malvern Nano ZS (Malvern Inc., UK) or a Brookhaven ZetaPALS (Brookhaven Instruments Corporation,

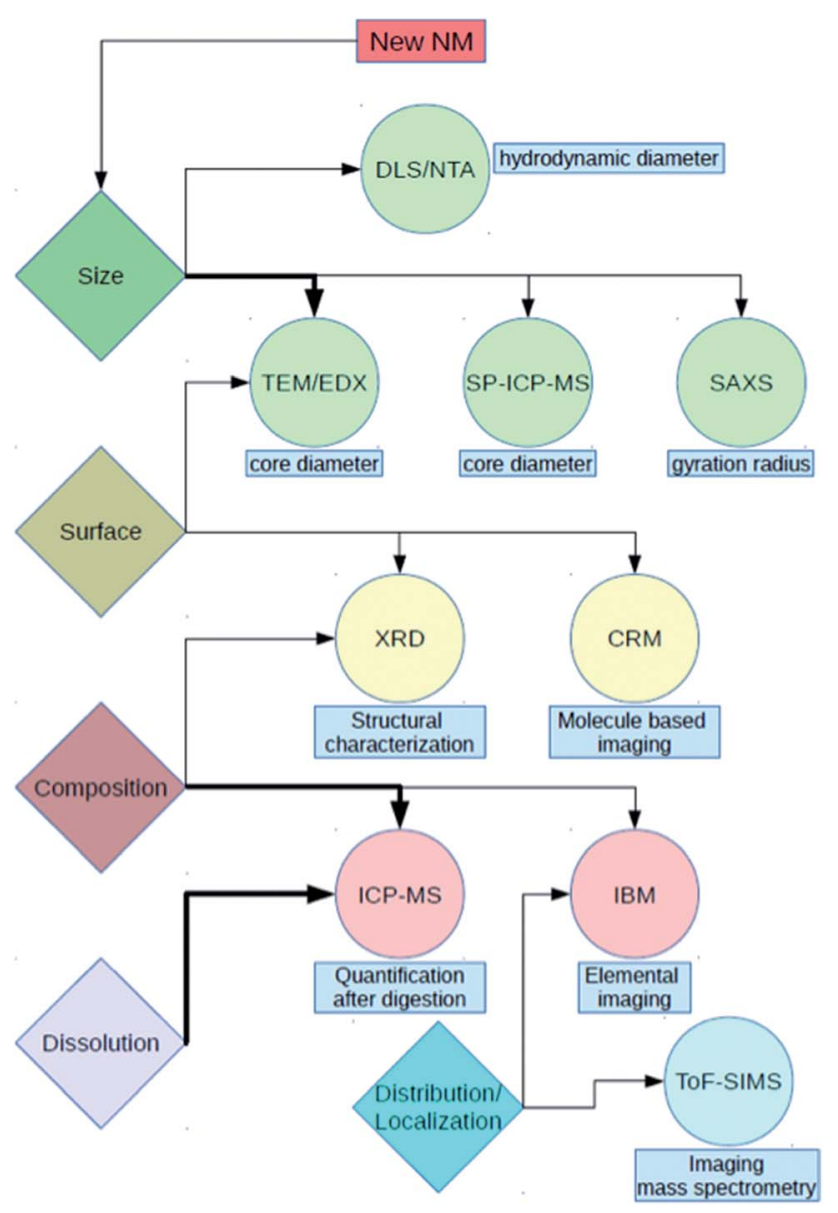

Fig. 2 Overview of key NM characteristics (colored rhombi) and methods (colored circles) used in this study for characterization. Arrows in bold imply the main method for the linked characteristic. Abbreviations: DLS - dynamic light scattering; NTA - nanoparticle tracking analysis; TEM - transmission electron microscopy; EDX energy dispersive $\mathrm{X}$-ray spectroscopy; SP-ICP-MS - single particle inductively coupled plasma mass spectrometry; SAXS - small angle Xray scattering; XRD - X-ray diffraction; CRM - confocal Raman microscopy; ICP-MS - inductively coupled plasma mass spectrometry; IBM - ion beam microscopy; ToF-SIMS - time of flight mass spectrometry.
USA). A stock dispersion (2.56 $\mathrm{mg} \mathrm{ml}^{-1}$ in $\left.0.05 \% \mathrm{BSA}\right)$ was

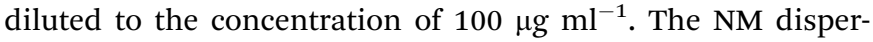
sions in $0.05 \%$ BSA as well as in DMEM were analyzed 5-10 min after preparation. Thermal equilibration time was set to $60 \mathrm{~s}$ at $25{ }^{\circ} \mathrm{C}$. Each intensity-weighted size distribution represents the average of six individual DLS analyses, three replicates and at least three independent experiments using automatic optimization of analytical conditions and data treatment by general purpose size analysis.

\section{Nanoparticle tracking analysis measurements}

NTA measurements were performed with a NanoSight LM20 and LM10 (NanoSight, Amesbury, UK), equipped with a $632 \mathrm{~nm}$ laser or $532 \mathrm{~nm}$ laser. The samples were injected into the sample chamber with sterile syringes. All measurements were performed at room temperature. The samples were diluted to a final concentration of approx. $10^{8}$ particles per ml with $\mathrm{mpH}_{2} \mathrm{O}$, depending on the NMs and media. The software used for recording and analyzing the data was NTA 2.3 and NTA 3.0. All samples were measured for $60 \mathrm{~s}$ at five positions. All measurements were performed with at least three independent experiments.

\section{X-ray diffraction measurements}

The XRD measurements were achieved on powder samples using a D5000 diffractometer (Siemens AG, Munich, Germany) in Bragg Brentano geometry. A linear detector, a curved Ge(111) monochromator and $\mathrm{Cu} \mathrm{K}_{\alpha}$ radiation $(\lambda=0.1542 \mathrm{~nm})$ were used. The analysis was performed over the $2 \theta$ range of 10 to $90^{\circ}$ and at a step size of $0.02^{\circ}$ and scanning speed of $2^{\circ}$ per step. The experiments were carried out independently three times.

\section{Single particle ICP-MS measurements}

For single particle analysis of the NM solutions, a quadrupole ICP-MS (Thermo Scientific XSERIES II, Thermo Fisher Scientific, Waltham, MA, USA) with a PFA ST Nebulizer, a quartz cyclonic spray chamber and a $2.5 \mathrm{~mm}$ quartz O-ring-free injector (all from ESI Elemental Service \& Instruments $\mathrm{GmbH}$, Mainz, Germany) were used. Using the time-resolved analysis (TRA) mode for data acquisition, intensities as a function of time (counts per dwell-time interval) were collected. The acquisition time for each run was set to $60 \mathrm{~s}$ with a dwell time (or data acquisition rate) of $3 \mathrm{~ms}$. The gas flow for the plasma, the nebulizer and the auxiliary (all Ar) was set to $131 \mathrm{~min}^{-1}, 0.89$ $1 \mathrm{~min}^{-1}$ and $0.71 \mathrm{~min}^{-1}$ respectively. The flow rate of the sample was $0.34 \mathrm{ml} \mathrm{min}{ }^{-1}$. Data were exported to a spreadsheet for further processing. For data processing, an established procedure according to Pace et al. ${ }^{29}$ was followed. Determination of nebulizer efficiency was performed using a described method with reference nanoparticles of known particle size. ${ }^{29} 60 \mathrm{~nm}$ gold reference nanoparticles from the U.S. National Institute of Standards and Technology (NIST, RM 8013) were used as reference nanoparticles. 


\section{Small angle $\mathrm{X}$-ray scattering measurements}

The measurements were conducted in a flow-through capillary with a Kratky-type instrument (SAXSess, Anton Paar, Austria) at $21 \pm 1{ }^{\circ} \mathrm{C}$. The SAXSess has a low sample-detector distance of $0.309 \mathrm{~m}$. Deconvolution of the SAXS curves was carried out with the SAXS-Quant software. Curve fitting was performed with the McSAS software (Monte Carlo method, version 1.0.1). The experiments were performed with 120 measurement cycles (each averaged over $10 \mathrm{~s}$ ). NMs and controls were dispersed according to NanoGenoTOX protocol and diluted into DMEM in a sample concentration of $100 \mu \mathrm{g} \mathrm{ml}^{-1}$. Samples were incubated for a time of 24 and $48 \mathrm{~h}$ at $37^{\circ} \mathrm{C}$ and $5 \% \mathrm{CO}_{2}$ in a cell incubator until sample injection. Stock dispersions were injected directly after ultrasonication.

\section{Ion beam microscopy}

Label-free IBM measurements were performed with the LIPSION Nanoprobe. A $2.25 \mathrm{MeV}$ proton beam was applied by a Singletron ${ }^{\mathrm{TM}}$ particle accelerator. A vacuum with a pressure of $5 \times 10^{-5}$ to $10^{-7}$ torr was applied and the beam was focused to a spot size of around $1 \mu \mathrm{m}$. For spatial resolved element analysis, micro proton induced X-ray emission ( $\mu$ PIXE) and micro Rutherford backscattering spectroscopy ( $\mu \mathrm{RBS})$ were recorded simultaneously. The $\mu$ PIXE detector (Canberra, Meriden, CT, USA) consists of a high-purity Ge crystal covered with a $60 \mu \mathrm{m}$ polyethylene layer, which covers the detector for backscattered protons. $\mu$ RBS spectra were detected by a Canberra PIPS detector.

\section{Confocal Raman microscopy}

Spectroscopic analysis of NMs was performed by CRM. A Witec alpha300 confocal Raman spectrometer (Witec GmbH, Germany) with a $532 \mathrm{~nm}$ laser with $30 \mathrm{~mW}$ power was used. Control4.1 (Witec GmbH, Germany) software was used to record and analyze the spectra. The spectra were recorded at an integration time of $0.15 \mathrm{~s}$ per point and with a step size of $250 \mathrm{~nm}$.

\section{Transmission electron microscopy}

The samples were deposited on a 400-mesh copper grid. The grids were prepared by sample adsorption and left free-standing on top of a $0.8 \mathrm{mg} \mathrm{ml}^{-1}$ solution of NMs for $20 \mathrm{~s}$. Excess solution was removed by placing the grid on a filter paper and the sample was dried for $24 \mathrm{~h}$. For samples in DMEM, the grid was washed by dipping the grid in a droplet of water before. Examination was performed with a JEOL 1400 transmission electron microscope, equipped with a tungsten filament and supplied with GATAN Orius 1000 camera. TEM operated at 80 $\mathrm{kV}(\mathrm{DMEM})$ or at $120 \mathrm{kV}$ with magnification of $200000 \times$.

\section{Time-of-flight mass spectrometry}

Ion images and spectra were acquired using a ToF-SIMS V instrument (ION-TOF GmbH, Münster, Germany) with a $30 \mathrm{keV}$ nano-bismuth primary ion beam source $\left([\mathrm{Bi}] x^{\left(y^{+}\right)}\right.$-cluster ion source with a BiMn emitter). The ion currents were $0.5 \mathrm{pA}$ at 5 $\mathrm{kHz}$ using a Faraday cup. A pulse of $0.7 \mathrm{~ns}$ from the bunching system resulted in a mass resolution that usually exceeded 6000 (full width at half-maximum) at $m / z<500$ in positive ion mode. The primary ion dose was controlled below 1012 ions $\mathrm{cm}^{-2}$ to ensure static SIMS conditions. Charge compensation on the sample was obtained by a pulsed electron flood gun with $20 \mathrm{eV}$ electrons.

The primary ion gun scanned a field of view of $500 \mu \mathrm{m} \times 500$ $\mu \mathrm{m}$ applying a $512 \times 512$ pixel measurement raster. Once the primary ion gun was aligned, a ToF-SIMS mass spectrum was generated by summing the detected secondary ion intensities and plotting them against the mass channels. The data were evaluated using the Surface Lab software (ION-TOF GmbH, Münster, Germany).

\section{Results and discussion}

We point to the advantages and disadvantages of the methods used and explain whether or not methods can provide complementary results to other techniques. We also analyzed possible dissolution characteristics of different matrix media (BSA and DMEM) for pristine $\mathrm{Al}^{0}$ and oxide $\left(\mathrm{Al}_{2} \mathrm{O}_{3}\right.$ and $\left.\mathrm{TiO}_{2}\right)$ NMs. Characterization data already published on $\mathrm{TiO}_{2}$ were retrieved according to JRC report. ${ }^{30}$ In conclusion, we will present data where the dissolution of NMs in complex media has an impact on particle media interactions. These results were obtained by ToF-SIMS and show the efficiency of that method for obtaining insights into elemental compositions with TEM, IBM, CRM and ToF-SIMS. An overview about the main characterization techniques and their limits is given in Table 3.

A very common and frequently used method for determining the size distribution and polydispersity of NMs in solution is DLS. Fast and easy sample preparation as well as quick measurement give rapid initial indications of the sample. NTA is more appropriate for evaluating polydisperse samples with

Table $1 Z$-averages with standard deviation (SD) and polydispersity index (PDI) of $\mathrm{Al}^{\circ}, \mathrm{Al}_{2} \mathrm{O}_{3}, \mathrm{NM} 103$ and NM104 NMs in different media determined by dynamic light scattering (DLS). All results represent the average of six repeats. BSA: bovine serum albumin; DMEM: Dulbecco's modified eagle medium; FCS: fetal calf serum

DLS measurements and comparison

$\frac{\text { Lab } 1 \text { (Malvern) }}{Z \text {-average [nm] PDI }} \quad \frac{\text { Lab 2 (Brookhaven) }}{Z \text {-average [nm] PDI }}$

Stock solution $\left(0.05 \%\right.$ BSA in $\left.\mathrm{H}_{2} \mathrm{O}\right)$

$\begin{array}{lllll}\mathrm{Al}^{0} \mathrm{NM} & 250 \pm 10 & 0.17 \pm 0.01 & 270 \pm 40 & 0.18 \pm 0.02\end{array}$

$\begin{array}{lllll}\mathrm{Al}_{2} \mathrm{O}_{3} \mathrm{NM} & 170 \pm 10 & 0.24 \pm 0.02 & 210 \pm 40 & 0.21 \pm 0.06\end{array}$

$\begin{array}{lllll}\text { NM103 } & 270 \pm 10 & 0.28 \pm 0.05 & 610 \pm 190 & 0.21 \pm 0.30\end{array}$

$\begin{array}{lllll}\text { NM104 } & 220 \pm 10 & 0.26 \pm 0.03 & 370 \pm 90 & 0.15 \pm 0.03\end{array}$

DMEM (with 10\% FCS)

$\begin{array}{lllll}\mathrm{Al}^{0} \mathrm{NM} & 200 \pm 10 & 0.18 \pm 0.01 & 220 \pm 10 & 0.21 \pm 0.02\end{array}$

$\begin{array}{lllll}\mathrm{Al}_{2} \mathrm{O}_{3} \mathrm{NM} & 70 \pm 10 & 0.52 \pm 0.03 & 230 \pm 60 & 0.18 \pm 0.07\end{array}$

$\begin{array}{lllll}\text { NM103 } & 240 \pm 20 & 0.24 \pm 0.01 & 270 \pm 10 & 0.25 \pm 0.01\end{array}$

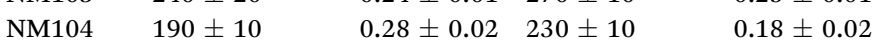


various aggregate populations, since it is based on single particle tracking as both techniques determine the hydrodynamic diameter. Due to the fixed working ranges of DLS and NTA, the used concentration of media various. Since NTA is a counting method, also proteins would be counted and would significantly lower the hydrodynamic diameter of the NM dispersion. Therefore, the particles, as well as the medium were diluted directly before measurement with $\mathrm{mpH}_{2} \mathrm{O}$ to avoid agglomeration effects.

For all particles with a primary size of approximately $20 \mathrm{~nm}$, a hydrodynamic diameter between 200 and $270 \mathrm{~nm}$ was measured by DLS in DMEM (Table 1). In contrast, different aggregate fractions of NMs in DMEM with a mean value of about $150 \mathrm{~nm}$ were found by means of NTA (Fig. S1†). This difference can be explained by the fact that NTA is a particle counting system, sensitive to large as well as small fractions in the sample, and DLS is an intensity-weighted system, highly responsive to the large fractions. In all cases, the NTA size distribution is asymmetrical with a steep slope on the left side (small particles) and a gentle slope on the right side, representing the fraction of agglomerates. Additionally, a calculation of number-based size distribution out of intensity-weighted DLS data was done (Table S1†).

In the case of NM103 and NM104 dispersed in 0.05\% BSA water solution, a very high mean value and a large error was measured by the Brookhaven device, while NTA exhibits broad distributions with some fractions and a mean value of around $180 \mathrm{~nm}$. This can be explained by unstable particle agglomerates, which are observed by the DLS.

Comparing the two DLS devices, one can observe that the Malvern DLS detects 15\% smaller particles than the Brookhaven machine in $0.05 \%$ BSA water solution as well as in DMEM. This systematic deviation could be related to different detection angles of scattered intensity, $90^{\circ}$ for Brookhaven and $173^{\circ}$ for Malvern, since larger particles mostly scatter light at forward angles. Backscattering at $173^{\circ}$ will not overestimate larger particles as much as measurements at $90^{\circ}$.

In the case of NM103 and 104 in BSA and $\mathrm{Al}_{2} \mathrm{O}_{3}$ in DMEM, the results were not consistent for the two devices. $Z$-averaged diffusion coefficients were calculated by applying the cumulant method, which is applicable to polydisperse and nonmultimodal systems. In contrast, NTA results show the presence of different particle populations. The applied cumulant algorithms are not suitable in certain cases for getting reliable DLS results. Furthermore, it should be kept in mind that the inversion of the DLS autocorrelation function is part of a poorly formulated mathematical problem. It works quite well in the case of monodisperse or low polydisperse particles. Applications of multiangle DLS and sophisticated algorithms are thus necessary to obtain trustworthy results of NM size distributions by means of DLS. ${ }^{31,32}$

\section{Investigations on primary particle size}

With the European commission's definition of a nanomaterial, that is, a nanomaterial should contain $50 \%$ or more particles in number size distribution with one or more size dimensions between 1-100 nm, it is obviously necessary to obtain information about the primary particle size of the investigated particles. TEM as well as SAXS can be used to solve this problem.

Looking at advantages and disadvantages of TEM, the following issues should be considered. Since TEM measurements are performed under high vacuum, only dried samples are observed. For this reason, TEM is not representative of the sample in its solution state. In particular, agglomeration and coffee stain effect $^{33}$ may occur during the drying process, resulting in a non-homogenously covered surface. Size distributions can be determined from TEM pictures by measuring the size of each particle using image analysis software. ${ }^{34}$ The size of individual nanoparticles may be difficult to extract from agglomerated samples but, recently, some implementations have been proposed..$^{35}$ In addition, for irregular particles with ill-defined shapes, which dimension should be taken? In practice, size analysis can be time-consuming and TEM generally yields a poor statistical representation of the sample. ${ }^{34}$ Electron microscopy also enables chemical and crystallographic analysis of the particles. The contrast in TEM is directly linked to the atomic number of electrons, heavier atoms giving higher contrast. This is an advantage when observing metal nanoparticles in a biological environment. However, care should be taken for mineral salts from buffers that may precipitate on the grid when drying. Aqueous washing of the grid after sample deposition might be appropriate in this case.

Fig. 3 shows the dispersion in water with $10 \%$ BSA. The shape of $\mathrm{Al}^{0} \mathrm{NMs}$ is globally spherical with rod-like excrescences and the primary particle size varies between 2-50 $\mathrm{nm}$, which matches the manufacturer specification. The $\mathrm{Al}_{2} \mathrm{O}_{3} \mathrm{NMs}$ are not spherical but have rather a needle-like shape. The width is about $10 \mathrm{~nm}$, while the longest dimension varies a bit more between $20-50 \mathrm{~nm}$. The shape of $\mathrm{TiO}_{2} \mathrm{NM} 104$ is rod-like, with a width of approx. $10 \mathrm{~nm}$ and length of 20-50 nm (Fig. S2 $\dagger$ ). Working with a more complex medium, such as CCM, was challenging for TEM analysis. However, we were able to image the particle in DMEM, with very little differences compared to BSA dispersion. Using relatively low voltage, the protein coating can be observed (see Fig. S2 $\dagger$ ).

SAXS was used for characterization of the primary particle size of NMs. SAXS allows to analyze a broader variety of different sample types than most other techniques. Compared to TEM, the samples can easily be investigated in situ. Additionally, SAXS provides statistically more reliable data for particle size distribution quantification since more than $10^{6}$ particles are typically measured, in contrast to TEM, where rarely more than a few

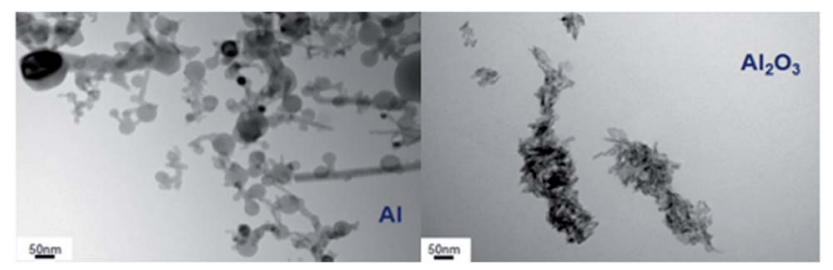

Fig. 3 Comparison of TEM pictures of $\mathrm{Al}^{\mathrm{O}}$ and $\mathrm{Al}_{2} \mathrm{O}_{3} \mathrm{NMS}$ in BSA solution after applying the dispersion protocol. 
hundred particles are counted. Size distribution of NMs can be quantified in the range of 1 to $100 \mathrm{~nm}$ if the shape is known from a complementary technique like TEM. The classical radius of gyration (Guinier radius) is accessible in any case.

In this study, we observed the size parameters of the particles in BSA as a stock solution and after addition in DMEM at different times of $t=0 \mathrm{~h}, 24 \mathrm{~h}$ and $48 \mathrm{~h}$ (Fig. 4). Since the particle cores scatter much stronger than the surrounding particle shell, the shell becomes practically invisible. Therefore, SAXS determines the size distribution of the core radii. The resulting distributions of the particles' stock solutions are shown in Fig. 4. Their corresponding SAXS curves are displayed in the ESI (Fig. S3-S5 $\dagger$ ). The accessible size range of the radii is given by the range of the scattering vector $q: R_{\min }=\pi / q_{\max }$ and $R_{\max }=\pi / q_{\min }$. In the present case of the $q$-range of $0.1 \mathrm{~nm}^{-1}<q$ $<6 \mathrm{~nm}^{-1}$ corresponds to radii of $30 \mathrm{~nm}>R>0.5 \mathrm{~nm}$.

The $\mathrm{Al}^{0}$ NMs showed a broad size distribution including primary particles with radii $>10 \mathrm{~nm}$. Since the detection limit is $30 \mathrm{~nm}$ (radius) in this case, bigger aggregates cannot be detected directly. However, from the steep slope of the SAXS curve (Fig. S3 $\dagger$ ) at low $q$ values, it can be assumed that bigger aggregates are present. The defined characterization of these particle aggregates has to be performed using a complementary method like TEM. The inset in Fig. 4a shows that the radii distribution of the $\mathrm{Al}^{0} \mathrm{NMs}$ did not change significantly either after addition in DMEM or $24 \mathrm{~h}$ and $48 \mathrm{~h}$ thereafter. In contrast to the $\mathrm{Al}^{0} \mathrm{NMs}$, the $\mathrm{Al}_{2} \mathrm{O}_{3} \mathrm{NM}$ in BSA displays a distribution which consists of small primary particles and aggregates. The sample shows an amount of $75 \%$ primary particles with a mean radius of $7.1 \pm$ $0.5 \mathrm{~nm}$. The detected aggregates display radii of $>10 \mathrm{~nm}$. Upon the addition in DMEM, the radii distribution shifts slightly to higher radii of $8.4 \pm 0.2 \mathrm{~nm}$. These characteristics did not change significantly over the time of $48 \mathrm{~h}$ in DMEM.
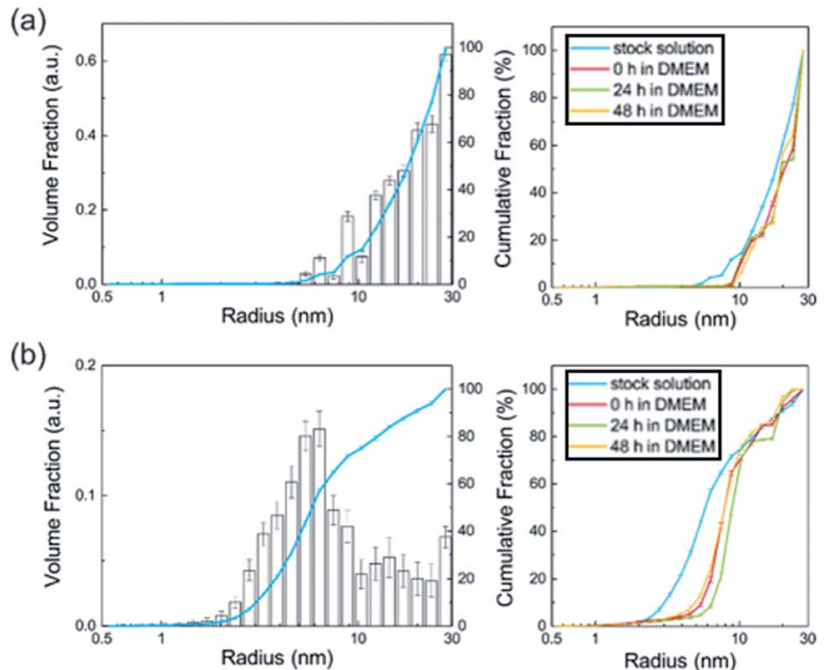

Fig. 4 Volume-weighted radii distributions of $\mathrm{Al}^{0} \mathrm{NMs}(\mathrm{a})$ and $\mathrm{Al}_{2} \mathrm{O}_{3}$ NMs (b) derived from SAXS measurements. The displayed radii distribution (right panel, black bars) and cumulative fraction presentation (blue line) correspond to the NMs in stock solution (BSA). Left panel shows particle distribution in cumulative fraction presentation at different stages: in stock solution (blue line) and in DMEM after $0 \mathrm{~h}$ (red line), $24 \mathrm{~h}$ (green line) and $48 \mathrm{~h}$ (orange line).
No particles were detected in the ionic control substance $\mathrm{AlCl}_{3}$. In contrast, immediately after addition in DMEM, nanoscaled particles with sizes of 1-30 nm were observed. Since all curves are background-corrected with the respective solvent control, solvent effects can be excluded and the particles derive directly from the aluminum species. In conclusion, SAXS yields the size distribution of nanoparticles and its changes in DMEM.

SP-ICP-MS is another technique to determine primary particle sizes. The fundamental assumption behind this technique is that, at a sufficiently short dwell time and low particle number concentration, a pulse will represent a single particle event.

There is a direct correlation between the number of pulses and the number concentration of particles (particle number per volume). With the intensity of the pulse (i.e. height) and assumptions about the particle geometry, the particle size through particle mass can be determined.

Aside from single pulses, there is always a background, which originates from the ionic part of the analyzed sample. In addition to primary particle size, information about the dissolution rate of a NM sample can be achieved. While quantification is more difficult, a qualitative assessment of ions released can be inferred. For $\mathrm{Al}^{0}$, a broad distribution (Fig. 5, left) up to $200 \mathrm{~nm}$ is observed compared to $\mathrm{Al}_{2} \mathrm{O}_{3}$ (Fig. 5, right). This fits very well with the data obtained from TEM analysis. Compared to the Au NIST reference material, which shows almost no dissolution, a higher background for $\mathrm{Al}^{0} \mathrm{NMs}$ was detected, indicating potential ion release.

\section{Particle surface - impact on dissolution in complex media}

$\mathrm{Al}^{0} \mathrm{NMs}$ usually become quickly passivated at the surface by the formation of an oxide layer. This event is likely to change the dissolution behavior and the overall physicochemical

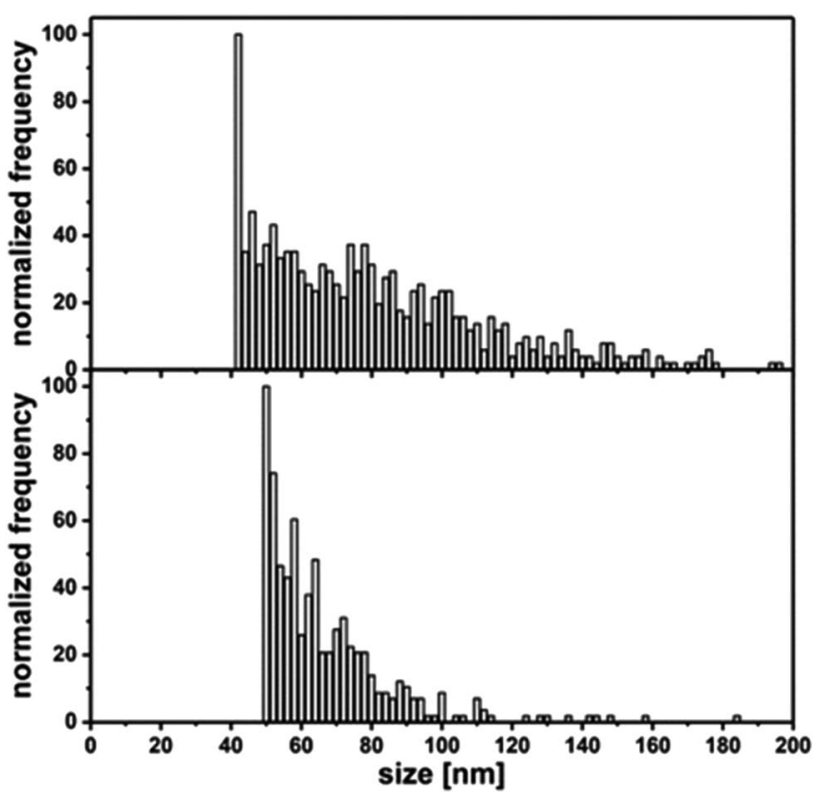

Fig. 5 Top: primary particle size distribution of $\mathrm{Al}^{0}$ in $0.05 \%$ BSA determined by SP-ICP-MS; bottom: Primary particle size distribution of $\mathrm{Al}_{2} \mathrm{O}_{3}$ in $0.05 \%$ BSA determined by SP-ICP-MS. 
characteristics of $\mathrm{Al}^{0} \mathrm{NMs}$. For comparison, we also investigated $\mathrm{Al}_{2} \mathrm{O}_{3}$ particles of similar size. To prevent the surface oxidation of $\mathrm{Al}^{0} \mathrm{NMs}$, its processing and handling in an inert gas atmosphere was evaluated.

Investigation by XRD revealed a thin aluminum oxide layer at the surface of the $\mathrm{Al}^{0}$ NMs (Fig. 6, left). This was confirmed by TEM measurements and has also already been shown in the literature for another $\mathrm{Al}^{0} \mathrm{NM}$ by TEM measurements $(2.5 \mathrm{~nm}$ oxide layer). ${ }^{36}$ The occurrence of an oxide layer can be explained by partial passivation of the material due to manufacturer's processing.

In comparison with $\mathrm{Al}^{0} \mathrm{NMs}$, the diffractogram of $\mathrm{Al}_{2} \mathrm{O}_{3}$ particles showed clear differences (Fig. 6, right). The diffractogram of $\mathrm{Al}^{0} \mathrm{NMs}$ showed a higher intensity for the aluminum peaks, e.g. at $38^{\circ}, 45^{\circ}, 66^{\circ}$ and $78^{\circ}$ (Fig. 6, left) as compared to $\mathrm{Al}_{2} \mathrm{O}_{3}$ peaks, e.g. at $37^{\circ}, 46^{\circ}$ and $67^{\circ}$ (Fig. 6, right). This demonstrates that even though there is an $\mathrm{Al}$ oxide layer at the surface of the Al NMs they are not completely oxidized.

To confirm these results, we used electron energy loss spectroscopy (EELS). Here the sample becomes exposed to an electron beam with defined kinetic energy. Some electrons undergoing inelastic scattering are collected in a detector. The loss of energy reflects the chemical composition of the sample.

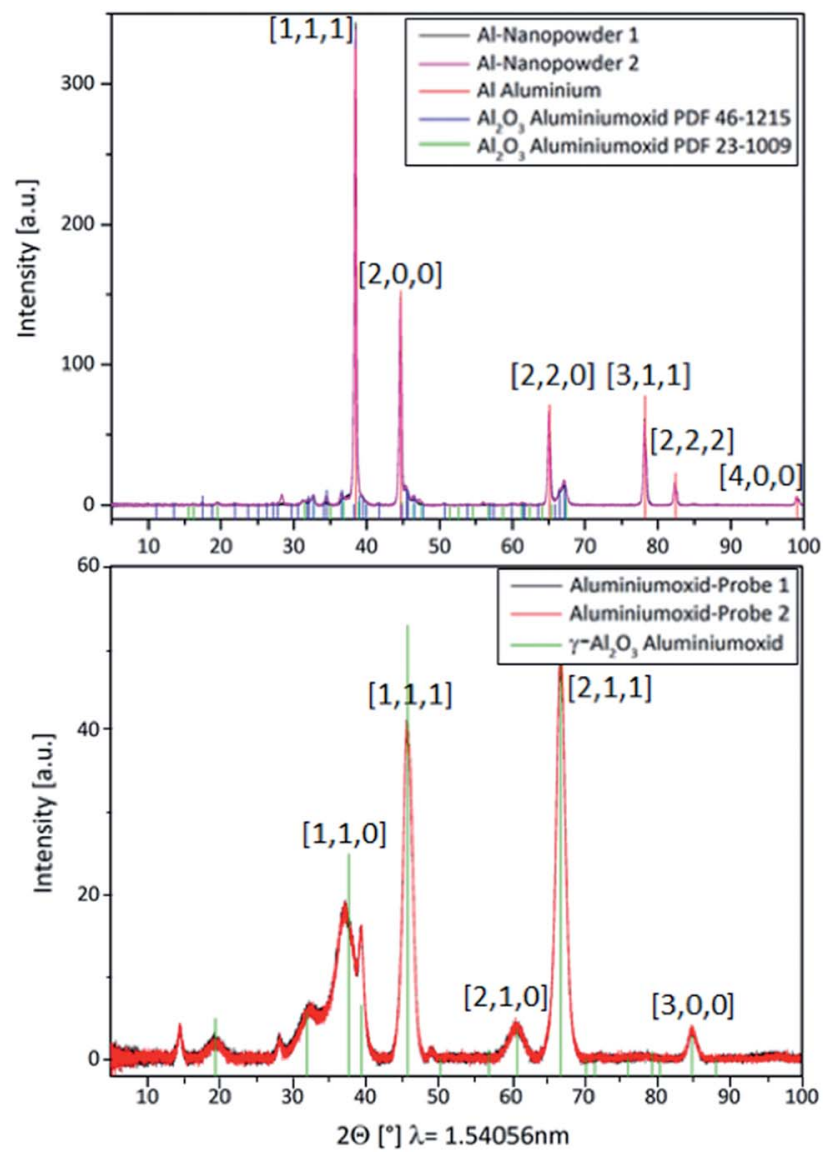

Fig. 6 Top: XR-diffractogram of $\mathrm{Al}^{\mathrm{O}} \mathrm{NMs}$ red: database entry for $\mathrm{Al}$; blue; (green: database entry for $\mathrm{Al}_{2} \mathrm{O}_{3}$ ), space group: $\mathrm{Fm} 3 \mathrm{~m}$, lattice constants: $a=4.0494 \AA$; bottom: diffractogram of $\mathrm{Al}_{2} \mathrm{O}_{3} \mathrm{NMs}$ (red: database entry for $\mathrm{Al}_{2} \mathrm{O}_{3}$ ), space group: Fd3m, lattice constants: $a=$ $7.906 \AA$.

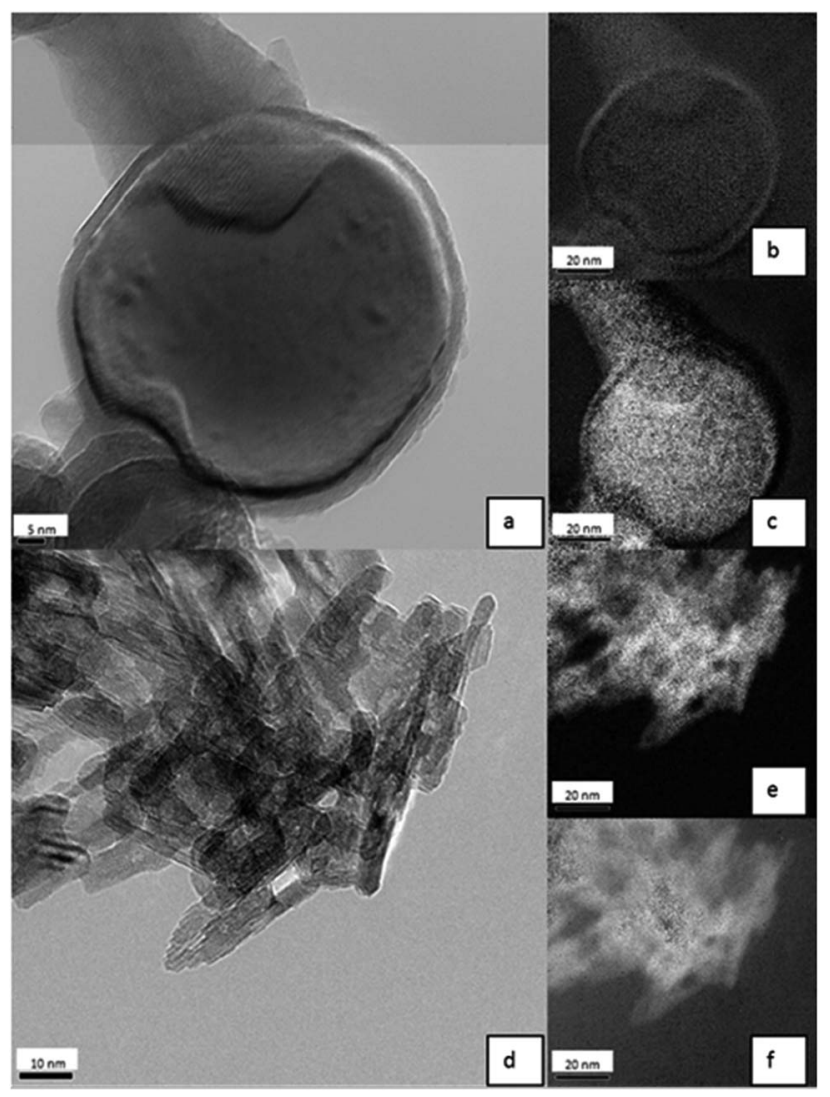

Fig. 7 (a): TEM picture of $\mathrm{Al}^{0} \mathrm{NMs}, 200 \mathrm{k}$ magnification; (b) oxygen mapping of left TEM picture; (c) Aluminum mapping of left TEM picture. (d) TEM picture of $\mathrm{Al}_{2} \mathrm{O}_{3} \mathrm{NMs}, 200 \mathrm{k}$ magnification; (e) aluminum mapping of left TEM picture; (f) oxygen mapping of left TEM picture.

Analysis of $\mathrm{Al}^{0} \mathrm{NMs}$ in $0.05 \%$ BSA (Fig. 7a) revealed a coreshell structure. By means of EELS, it was proven that the shell is rich in oxygen (Fig. 7b), while the core consists of elemental aluminum (Fig. 7c). The TEM results indicate an oxide layer of about 2 to $5 \mathrm{~nm}$.

Elemental mapping of $\mathrm{Al}_{2} \mathrm{O}_{3}$ NMs showed a quite different picture compared to pure $\mathrm{Al}^{0} \mathrm{NMs}$ (Fig. 7d). The distribution of aluminum and oxygen was homogenous over all NMs (Fig. 7e and f). These results show that $\mathrm{Al}_{2} \mathrm{O}_{3} \mathrm{NMs}$ are fully oxidized while elemental $\mathrm{Al}^{0} \mathrm{NMs}$ were passivated by an oxide layer. It is

Table 2 Ion release of $\mathrm{Al}^{0}$ and $\mathrm{Al}_{2} \mathrm{O}_{3} \mathrm{NMs}$ compared to recovery of $\mathrm{AlCl}_{3}$ in $0.05 \% \mathrm{BSA}$ and DMEM

\begin{tabular}{llcc}
\hline & & $\begin{array}{c}\text { Ion release } \\
\text { in BSA [\%] }\end{array}$ & $\begin{array}{l}\text { Ion release in } \\
\text { DMEM [\%] }\end{array}$ \\
\hline $\mathrm{Al}^{0} \mathrm{NMs}$ & $10 \mu \mathrm{g} \mathrm{ml}^{-1}$ & $0.4 \pm 0.1$ & $0.5 \pm 0.1$ \\
$\mathrm{Al}_{2} \mathrm{O}_{3} \mathrm{NMs}$ & $100 \mu \mathrm{g} \mathrm{ml}^{-1}$ & $0.3 \pm 0.1$ & $0.4 \pm 0.1$ \\
& $10 \mu \mathrm{g} \mathrm{ml}^{-1}$ & $0.4 \pm 0.1$ & $1.4 \pm 0.1$ \\
$\mathrm{AlCl}_{3}$ & $100 \mu \mathrm{g} \mathrm{ml}^{-1}$ & $0.2 \pm 0.1$ & $0.4 \pm 0.1$ \\
& $10 \mu \mathrm{g} \mathrm{ml}^{-1}$ & $140 \pm 9$ & $112 \pm 4$ \\
& $100 \mu \mathrm{g} \mathrm{ml}^{-1}$ & $94 \pm 4$ & $66 \pm 3$
\end{tabular}



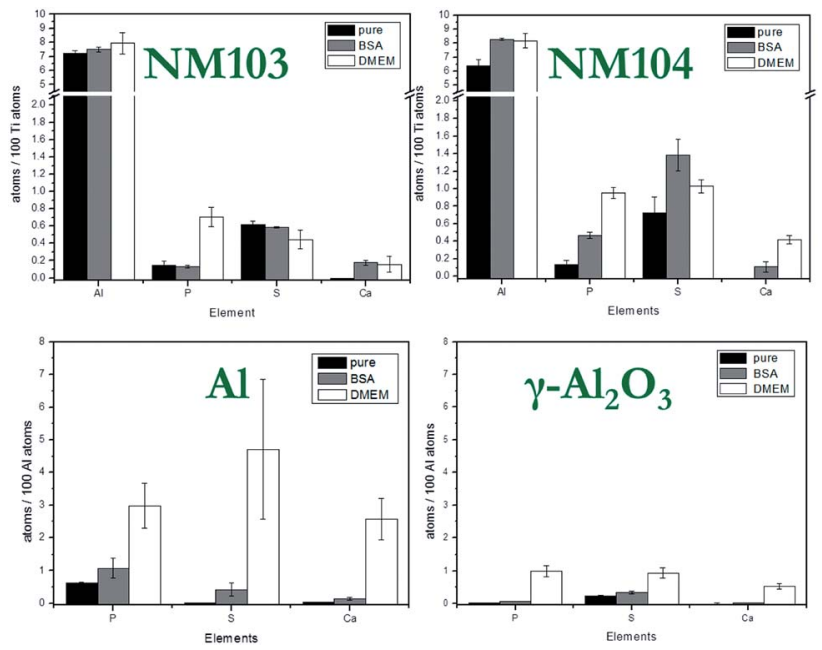

Fig. 8 IBM element analysis of NM103, NM104, $\mathrm{Al}$ and $\mathrm{Al}_{2} \mathrm{O}_{3} \mathrm{NMs}$. NMs as purchased and diluted in water (pure), NMs with albumin corona in $\mathrm{H}_{2} \mathrm{O}$ (BSA) and NMs under cell exposure conditions (DMEM). The graph demonstrates the ratio of atoms of several elements compared to 100 atoms of titanium or aluminum.

also visible because $\mathrm{Al}^{0} \mathrm{NMs}$ are dark grey to black, while $\mathrm{Al}_{2} \mathrm{O}_{3}$ NMs are white.

The results from surface investigations via XRD and EELS suggest a different solubility of $\mathrm{Al}^{0}$ compared to $\mathrm{Al}_{2} \mathrm{O}_{3}$. Indeed, the thin oxide layer on $\mathrm{Al}^{0}$ allows the release of ions while the fully oxidized $\mathrm{Al}_{2} \mathrm{O}_{3}$ particle should be much more inert. Nevertheless, due to the highly specific surface, a higher solubility compared to $\mathrm{Al}_{2} \mathrm{O}_{3}$ bulk material could be expected as more potentially ion releasing $\mathrm{Al}$ atoms are present on the surface.

\section{Influence of particle composition and impurity patterns}

Compared to particle size and surface, the particle composition has a much higher impact on the solubility and dissolution behavior of NMs. One of the most widely used methods due to its high sensitivity, broad range for nearly all elements and detection limits down to the sub-ppb level is the ICP-MS. Unknown samples can be not only detected but also quantified. For more complex samples, microwave-assisted digestion prior to ICP-MS analysis could be performed. In this study, we confirmed the already known composition of the NMs by XRD and EELS measurements as well as ICP-MS analysis. For the assessment of particle toxicity, it is also important to take impurities into account which might alter ion release behavior. Due to element-specific $\mu$ RBS and $\mu$ PIXE, IBM became the method of choice for these investigations. The main impurities of aluminum-containing NMs were phosphorus, sulfur and chlorine, which could lead to a different ion release compared to pure materials (see Fig. S6†).

\section{Solubility investigations on $\mathrm{Al}^{\mathbf{0}}$ and $\mathrm{Al}_{2} \mathrm{O}_{3} \mathrm{NMs}$}

To verify our hypothesis that $\mathrm{Al}^{0} \mathrm{NMs}$ are more soluble than $\mathrm{Al}_{2} \mathrm{O}_{3}$, we performed ion release experiments in stock dispersions and DMEM. Adjusting the $\mathrm{pH}$ value was not necessary due to almost neutral $\mathrm{pH}$ values of 7.3 in stock dispersion compared to 7.2 in DMEM. Keeping in mind that aluminum is an amphoteric material due to the aluminum aqua complexes, one can assume that dissolution of $\mathrm{Al}^{0} \mathrm{NMs}$ in complex media is highly pH-dependent. Compared to an acid, the aluminum aqua complex reacts as a base and vice versa. At a neutral $\mathrm{pH}$ value, reactivity is very low, thus only low ion release should occur. The possible aluminum aqua complexes at the different $\mathrm{pH}$ values are shown in Fig. S7. $\dagger$

The ion release for both $\mathrm{Al}^{0}$ and $\mathrm{Al}_{2} \mathrm{O}_{3} \mathrm{NMs}$ after one hour was very low, about $0.2-0.4 \%$ in BSA and $0.3-0.5 \%$ in DMEM (with 10\% FCS) (Table 2). As already described above, this was expected at a neutral $\mathrm{pH}$ value. For in vitro experiments, this will

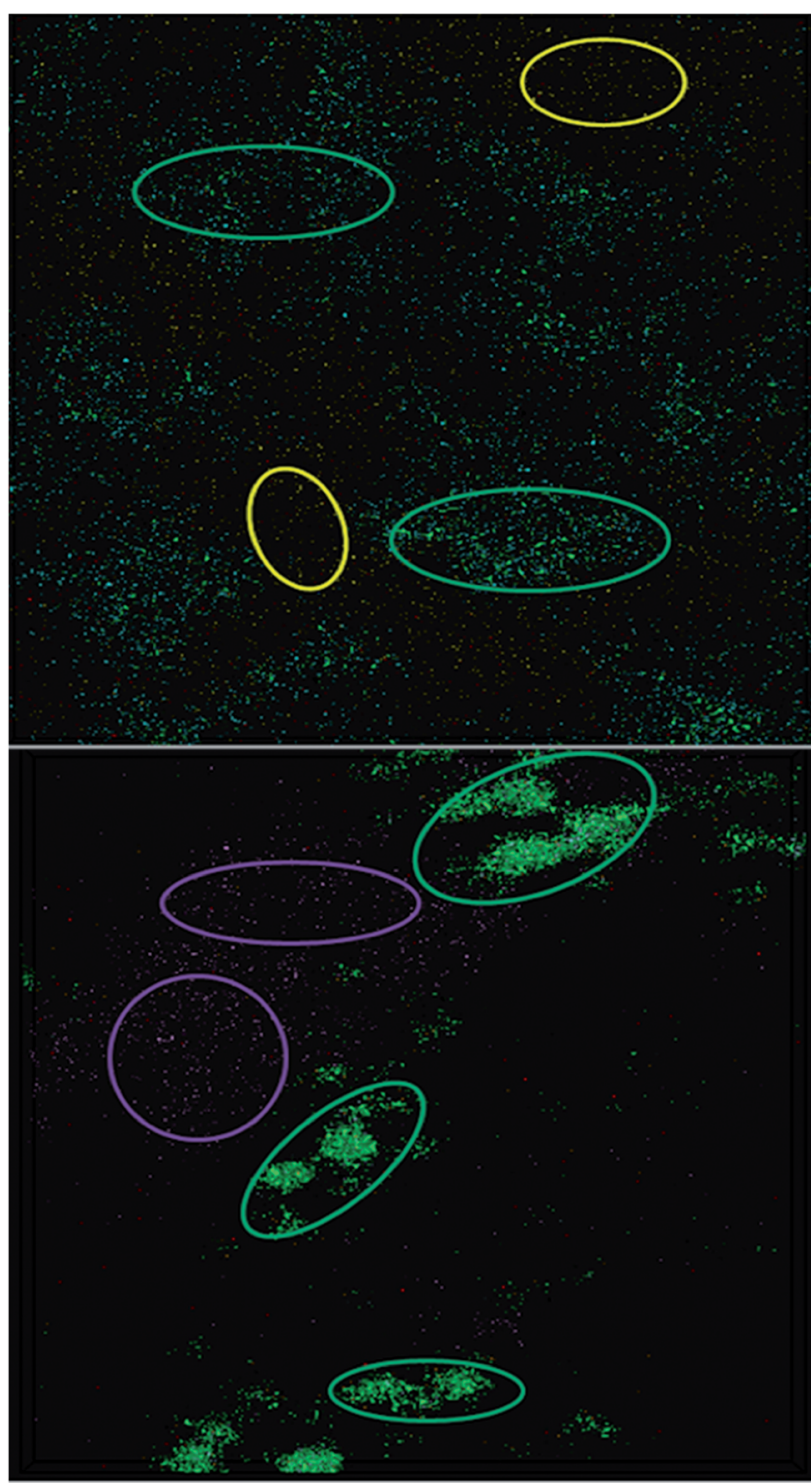

Fig. 9 ToF-SIMS reconstructed ion overlay image $(500 \mu \mathrm{m} \times 500 \mu \mathrm{m})$ of $\mathrm{Al} \mathrm{NM}$ (top) and $\mathrm{Al}_{2} \mathrm{O}_{3}$ (bottom) agglomerates of different chemical entities from a DMEM solution; yellow: $\mathrm{Al} N \mathrm{NM}$, purple: $\mathrm{Al}_{2} \mathrm{O}_{3} \mathrm{NM}$, green: aluminum(II)-serine; orange: phenylalanine aluminate; red: leucine aluminate; blue: polyoxo-aluminum complex. 

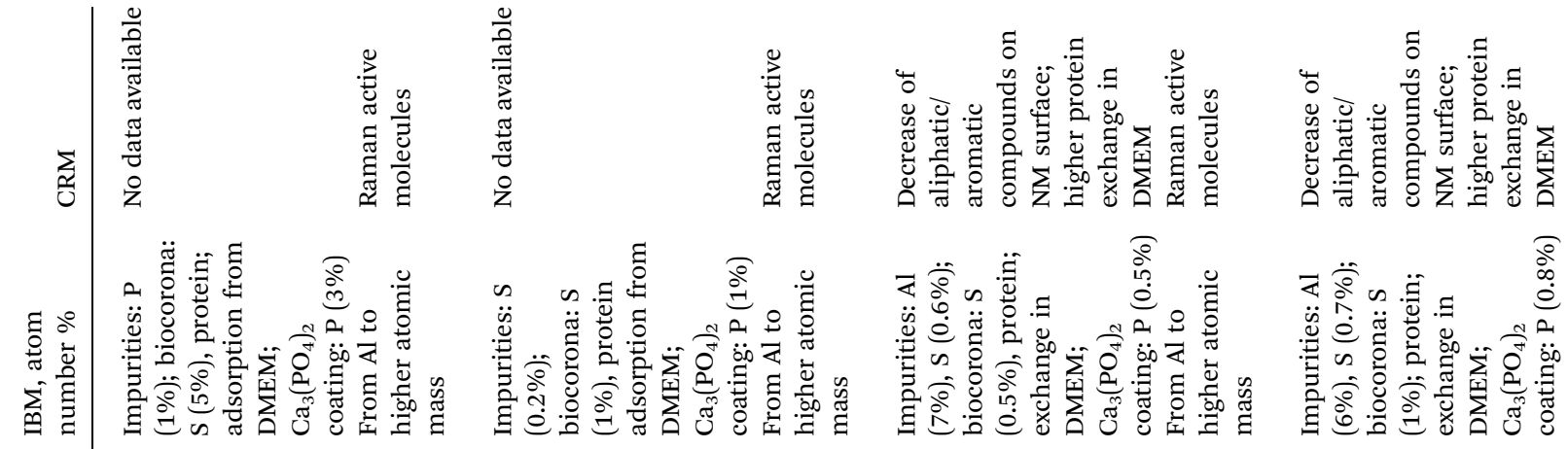

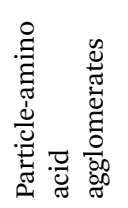

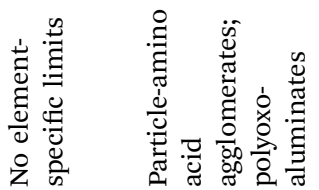

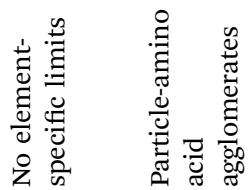

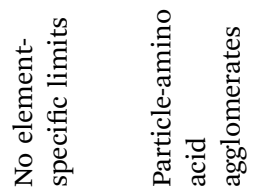

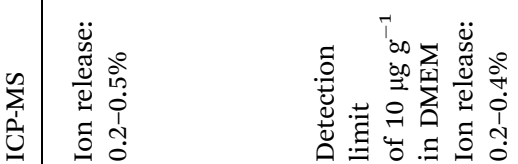

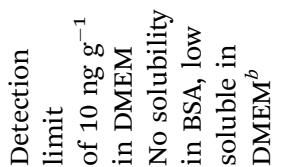

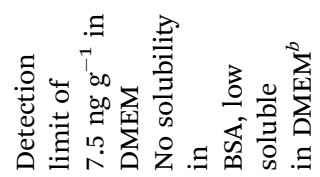

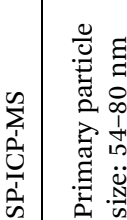

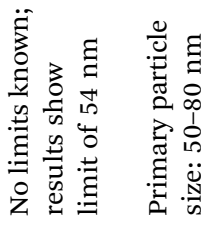

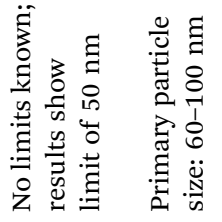

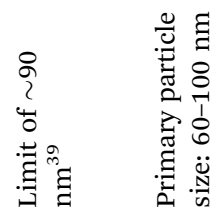

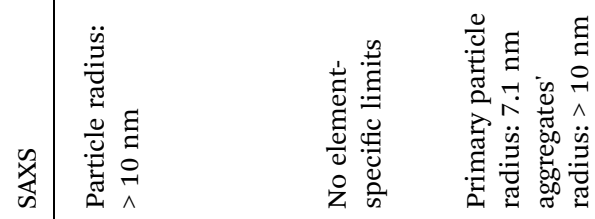

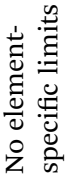

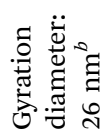

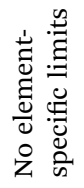

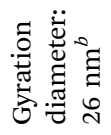

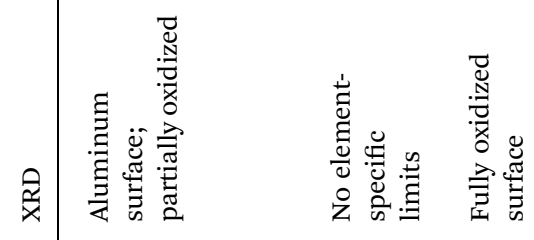

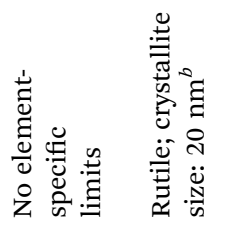

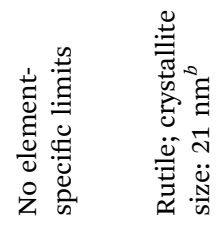

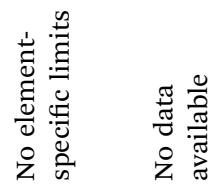

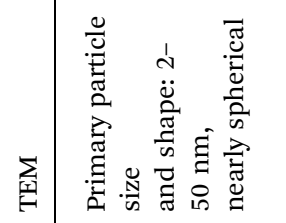

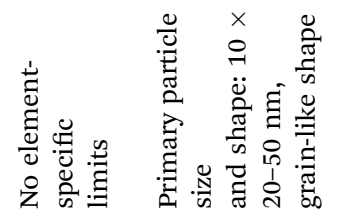

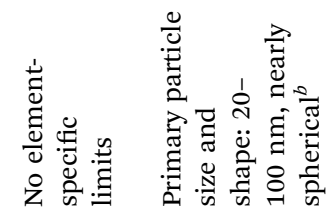

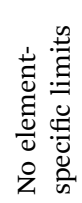

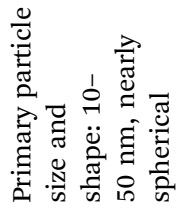

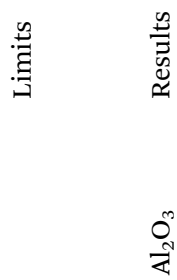

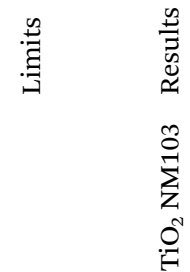

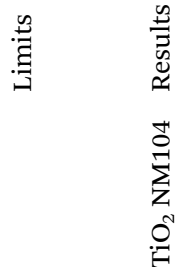




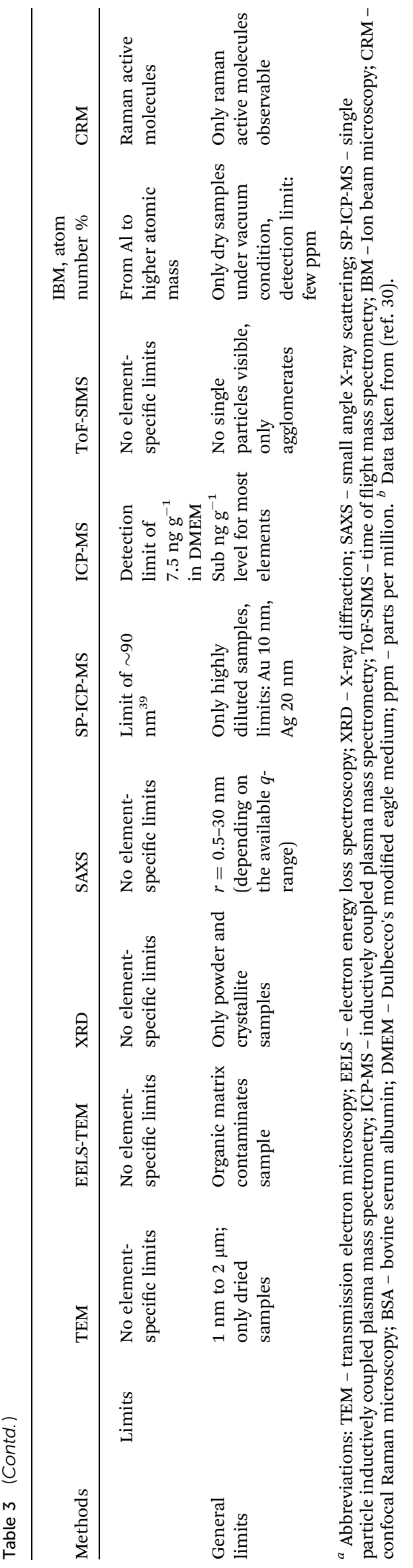

mean that the effects will originate mainly from particles and not from $\mathrm{Al}$ ions. The application of an artificial digestion procedure for mimicking in vivo situation showed, that the particle dissolution and complexation behavior was quite different in all three studied gastrointestinal compartments. ${ }^{24}$ After no significant changes in the saliva, the gastric environment leads to a significant increase of the dissolution rate as well as very strong agglomeration of NMs. The addition of intestinal fluid results in a nearly neutral $\mathrm{pH}$ value which leads to a decrease in the dissolution rate, a deagglomeration of particles and even de novo particle formation in ionic aluminum control.

\section{Particle-CCM interactions}

It is of major interest to evaluate the elemental and molecular changes on the particle surface during sample preparation for cell experiments (Fig. S8 and S9†). Additionally, two steps were chosen to investigate the surface modification of particles during the sample preparation process. Firstly, the NMs were dispersed. In this step, NMs were covered with albumin corona and are referred to as "BSA" in the text below. The second step was to investigate the NMs under cell culture conditions, diluted in DMEM. After each step, the particles were washed three times in Millipore water. The results of the element analysis, performed by IBM, are shown in Fig. 8.

The variation of the element content represents changes on the surface of NMs, e.g. attachment of amino acids, fatty acids, proteins and/or ions to the surface of the NMs. An increase in the Ca and P amount was observed for all studied NMs exposed to DMEM. The highest content of these elements was found in the case of Al NMs. It is suggested that calcium and phosphate ions interact strongly with the albumin corona of NMs and build a calcium phosphate layer on the particle surface. It is known that calcium phosphate has a high affinity to proteins and can increase the efficiency of uptake. ${ }^{37,38}$

The amount of sulfur on the NMs was analyzed under different conditions. Sulfur was found in association with proteins forming a corona around the $\mathrm{NMs}$. $\mathrm{Al}$ and $\mathrm{Al}_{2} \mathrm{O}_{3} \mathrm{NMs}$ acquire more proteins on their surface when exposed to DMEM as compared to dispersion in $0.05 \%$ BSA (Fig. S11†). In the case of $\mathrm{Al}$ and $\mathrm{Al}_{2} \mathrm{O}_{3}$, the proteins from the culture medium contribute to additional adsorption compared to the existing albumin corona of the particles alone. DMEM shows more physiologic relevant conditions. The salts might induce shielding effects on the protein, so the amount of proteins is likely to be increased. Due to the larger variety of available proteins, a more complex corona will self-assemble on the surface of the particles. In contrast, a decreased amount of proteins was found in the case of NM103 and 104 NMs exposed to DMEM. Substitution of the relatively dense BSA on the particle surface with less dense proteins from the culture media is suggested. This exchange of proteins has a stabilizing effect on $\mathrm{TiO}_{2}$ NMs in DMEM and results in a strong decrease of aggregate size in DMEM media (Table 1). This finding is also supported by CRM investigations (Fig. S10†). 
ToF-SIMS was used to image $\mathrm{Al}$ NMs and $\mathrm{Al}_{2} \mathrm{O}_{3} \mathrm{NMs}$ as well as nanoparticle agglomerates in cell culture medium and to assess the chemical composition of the nanoparticle agglomerates. The analyses revealed nanoparticle-specific agglomerates, consisting of polyoxo-aluminum complexes, aluminum(III)-serine and amino acid aluminate complexes (leucine and phenylalanine aluminate). These complexes were not observed when ionic $\mathrm{AlCl}_{3}$ was added to the cell culture medium. ToF-SIMS images revealed a rather homogenous agglomerate distribution with only a slight accumulation of $\mathrm{Al} \mathrm{NMs} \mathrm{in} \mathrm{certain} \mathrm{areas} \mathrm{(see} \mathrm{yellow} \mathrm{circles} \mathrm{in} \mathrm{Fig.} \mathrm{9,} \mathrm{top)}$ and aluminum(III)-serine and polyoxo-aluminum complexes in others (see green circles in Fig. 9, top). While the aluminates colocate with both areas, aluminates can be found in regions with predominantly $\mathrm{Al} \mathrm{NMs}$ and in areas with predominantly aluminum(III)-serine and polyoxo-aluminum. Fig. 9 shows the ToF-SIMS image for $\mathrm{Al}_{2} \mathrm{O}_{3} \mathrm{NMs}$ (bottom). Larger agglomerate areas (green circles in Fig. 9, bottom), where aluminum(III)-serine and polyoxoaluminum complexes were present in higher amounts, can be distinguished from areas with predominantly smaller nanoparticle agglomerates made of $\mathrm{Al}_{2} \mathrm{O}_{3}$ NMs (see purple circles in Fig. 9, bottom).

In DMEM with $\mathrm{Al} \mathrm{NMs,} \mathrm{areas} \mathrm{where} \mathrm{predominantly} \mathrm{Al} \mathrm{NMs}$ localize, depicted as yellow circles in Fig. 9, top, are distinct from areas where polyoxo-aluminum complexes and aluminum(III)-serine particles localize (green circles). Generally, smaller agglomerates of different chemical entities, Al NMs, aluminum(III)-serine, leucine aluminate, phenylalanine aluminate and polyoxo-aluminum complexes, which do not colocalize in the same area, were observed. In addition to areas where predominantly $\mathrm{Al}_{2} \mathrm{O}_{3} \mathrm{NMs}$ (purple) localize, $\mathrm{Al}_{2} \mathrm{O}_{3} \mathrm{NMs}$ in DMEM show a similar pattern with areas where all chemical entities co-localize but are clearly separated from each other. This indicates a starting mineralization of the larger agglomerates, where different chemical entities co-localize and form mixed agglomerates of $\mathrm{Al}_{2} \mathrm{O}_{3} \mathrm{NMs}$, amino acids and aluminum salts. Further agglomerate compositions and chemical entities were detected (Fig. S11-14†). For ToF-SIMS measurements for $\mathrm{TiO}_{2}$ NM103 and 104 in DMEM see Fig. S15-18. $\dagger$

\section{Conclusions}

An extensive characterization of NMs in their different states, from dispersion to in vitro conditions, should precede any toxicological testing. In this study, we have characterized two different types of NMs, one metal and one metal oxide. For this purpose, we used a wide range of complementary analytical techniques to characterize particle size, surface and composition in more detail. An indepth insight into the dissolution, one of the most important determinants of NM toxicity, was achieved by investigation by the examples of $\mathrm{Al}^{0}$ and $\mathrm{Al}_{2} \mathrm{O}_{3}$ NMs. A very low dissolution rate and a small percentage of ion release was observed at a neutral $\mathrm{pH}$ value, while higher rates for acidic environment we already reported earlier. ${ }^{24} \mathrm{~A}$ significant difference between the surface and the extent of oxidation of $\mathrm{Al}^{0}$ and $\mathrm{Al}_{2} \mathrm{O}_{3} \mathrm{NM}$ forms was detected. In contrast to the fully oxidized $\mathrm{Al}_{2} \mathrm{O}_{3}$ with a rather homogenous distribution of $\mathrm{Al}$ and $\mathrm{O}$ atoms, $\mathrm{Al}^{0} \mathrm{NM}$ showed a core-shell structure with an oxide layer only a few $\mathrm{nm}$ thick. This was proven with XRD and the EELS technique, which emphasizes the benefit of using different techniques to get reliable results. It was demonstrated with the help of ToF-SIMS that both aluminum forms are subject to a surprisingly different complexation in biological media: while $\mathrm{Al}^{0} \mathrm{NMs}$ were shown to form complexes with amino acids, $\mathrm{Al}_{2} \mathrm{O}_{3} \mathrm{NMs}$ mostly formed polyoxo-complexes out of two or more $\mathrm{Al}_{2} \mathrm{O}_{3}$ molecules. Based on the collected results, all of the investigation methods applied have their own benefits. Thus, with the methods described in this study focusing on size, surface and complex formation, dissolution investigations can perhaps become a bit more predictable. Right now, the recommended limit for aluminum release from food is $5 \mathrm{mg} \mathrm{kg}{ }^{-1}$ food. The various aluminum forms, e.g. ions, micro- and nanomaterials, pure $\mathrm{Al}^{0}$ or $\mathrm{Al}_{2} \mathrm{O}_{3}$, are not differentiated here. With this study, it becomes obvious that there should be differentiation for the different forms, as they may be taken up and react differently. For future analytical investigations on aluminum-containing $\mathrm{NMs}$, we propose considering not only $\mathrm{Al}_{2} \mathrm{O}_{3}$ but also $\mathrm{Al}^{0} \mathrm{NMs}$ and their interaction with the corresponding ions.

\section{Conflicts of interest}

There are no conflicts to declare.

\section{Acknowledgements}

This French-German bilateral project SolNanoTOX was funded by the German Research Foundation (DFG, Project ID: DFG (FKZ LA 3411/1-1 and LA 1177/9-1)) and the French National Research Agency (ANR, Project ID: ANR-13-IS10-0005). The authors would like to thank Simone Rolf from the Federal Institute for Materials Research and Testing (BAM) for the XRD measurements, Claudia Kästner from BAM for the SAXS measurements and Dr Uwe Mühle from the Fraunhofer Institute for Ceramic Technologies and Systems (IKTS) for the TEM measurements with elemental information.

\section{Notes and references}

1 A. Moores and F. Goettmann, New J. Chem., 2006, 30, 11211132.

2 K. L. Kelly, E. Coronado, L. L. Zhao and G. C. Schatz, J. Phys. Chem. B, 2003, 107, 668-677.

3 D. M. Brown, M. R. Wilson, W. MacNee, V. Stone and K. Donaldson, Toxicol. Appl. Pharmacol., 2001, 175, 191-199.

4 S. Hussain, S. Boland, A. Baeza-Squiban, R. Hamel, L. C. J. Thomassen, J. A. Martens, M. A. Billon-Galland, J. Fleury-Feith, F. Moisan, J. C. Pairon and F. Marano, Toxicology, 2009, 260, 142-149.

5 Y. Zhang, N. Kohler and M. Q. Zhang, Biomaterials, 2002, 23, 1553-1561.

6 A. Cockburn, R. Bradford, N. Buck, A. Constable, G. Edwards, B. Haber, P. Hepburn, J. Howlett, F. Kampers, C. Klein, M. Radomski, H. Stamm, S. Wijnhoven and T. Wildemann, Food Chem. Toxicol., 2012, 50, 2224-2242.

7 I. A. Rahman, P. Vejayakumaran, C. S. Sipaut, J. Ismail and C. K. Chee, Mater. Chem. Phys., 2009, 114, 328-332. 
8 S. E. A. Gratton, P. A. Ropp, P. D. Pohlhaus, J. C. Luft, V. J. Madden, M. E. Napier and J. M. DeSimone, Proc. Natl. Acad. Sci. U. S. A., 2008, 105, 11613-11618.

9 Y. Zhou and M. Antonietti, J. Am. Chem. Soc., 2003, 125, 14960-14961.

10 S. K. Das, M. K. Bhunia and A. Bhaumik, Dalton Trans., 2010, 39, 4382-4390.

11 Z. Q. Sun, T. Liao, L. Y. Sheng, L. Z. Kou, J. H. Kim and S. X. Dou, Chem.-Eur. J., 2016, 22, 11357-11364.

12 X. N. Ren, L. Wu, J. Jin, J. Liu, Z. Y. Hu, Y. Li, T. Hasan, X. Y. Yang, G. Van Tendeloo and B. L. Su, RSC Adv., 2016, 6, 26856-26862.

13 M. Moreno-Horn and T. Gebel, Crit. Rev. Toxicol., 2014, 44, 849-875.

14 J. X. Wang, G. Q. Zhou, C. Y. Chen, H. W. Yu, T. C. Wang, Y. M. Ma, G. Jia, Y. X. Gao, B. Li, J. Sun, Y. F. Li, F. Jiao, Y. L. Zhao and Z. F. Chai, Toxicol. Lett., 2007, 168, 176-185. 15 E. J. Park, H. Kim, Y. Kim and K. Choi, Toxicol. Environ. Chem., 2011, 93, 120-133.

16 Y. R. Kim, S. Y. Lee, E. J. Lee, S. H. Park, N. W. Seong, H. S. Seo, S. S. Shin, S. J. Kim, E. H. Meang, M. K. Park, M. S. Kim, C. S. Kim, S. K. Kim, S. W. Son, Y. R. Seo, B. H. Kang, B. S. Han, S. S. Aan, B. J. Lee and M. K. Kim, Int. J. Nanomed., 2014, 9, 67-78.

17 K. Loeschner, N. Hadrup, K. Qvortrup, A. Larsen, X. Y. Gao, U. Vogel, A. Mortensen, H. R. Lam and E. H. Larsen, Part. Fibre Toxicol., 2011, 8, 18.

18 J. H. E. Arts, M. Hadi, A. M. Keene, R. Kreiling, D. Lyon, M. Maier, K. Michel, T. Petry, U. G. Sauer, D. Warheit, K. Wiench and R. Landsiedel, Regul. Toxicol. Pharmacol., 2014, 70, 492-506.

19 A. R. Collins, B. Annangi, L. Rubio, R. Marcos, M. Dorn, C. Merker, I. Estrela-Lopis, M. R. Cimpan, M. Ibrahim, E. Cimpan, M. Ostermann, A. Sauter, N. E. Yamani, S. Shaposhnikov, S. Chevillard, V. Paget, R. Grall, J. Delic, F. G. de-Cerio, B. Suarez-Merino, V. Fessard, K. N. Hogeveen, L. M. Fjellsbo, E. R. Pran, T. Brzicova, J. Topinka, M. J. Silva, P. E. Leite, A. R. Ribeiro, J. M. Granjeiro, R. Grafstrom, A. Prina-Mello and M. Dusinska, Wiley Interdiscip. Rev.: Nanomed. Nanobiotechnol., 2017, 9, e1413.

20 P. Laux, C. Riebeling, A. M. Booth, J. D. Brain, J. Brunner,

C. Cerrillo, O. Creutzenberg, I. Estrela-Lopis, T. Gebel, G. Johanson, H. Jungnickel, H. Kock, J. Tentschert, A. Tlili, A. Schäffer, A. J. A. M. Sips, R. A. Yokel and A. Luch, NanoImpact, 2017, 6, 69-80.

21 J. M. Cohen, J. G. Teeguarden and P. Demokritou, Part. Fibre Toxicol., 2014, 11, 20.

22 S. Dekkers, A. G. Oomen, E. A. J. Bleeker, R. J. Vandebriel, C. Micheletti, J. Cabellos, G. Janer, N. Fuentes, S. VazquezCampos, T. Borges, M. J. Silva, A. Prina-Mello, D. Movia, F. Nesslany, A. R. Ribeiro, P. E. Leite, M. Groenewold, F. R. Cassee, A. J. A. M. Sips, A. Dijkzeul, T. van Teunenbroek and S. W. P. Wijnhoven, Regul. Toxicol. Pharmacol., 2016, 80, 46-59.

23 A. D. Maynard, R. J. Aitken, T. Butz, V. Colvin, K. Donaldson, G. Oberdorster, M. A. Philbert, J. Ryan, A. Seaton, V. Stone,
S. S. Tinkle, L. Tran, N. J. Walker and D. B. Warheit, Nature, 2006, 444, 267-269.

24 H. Sieg, C. Kastner, B. Krause, T. Meyer, A. Burel, L. Bohmert,

D. Lichtenstein, H. Jungnickel, J. Tentschert, P. Laux,

A. Braeuning, I. Estrela-Lopis, F. Gauffre, V. Fessard, J. Meijer, A. Luch, A. F. Thunemann and A. Lampen, Langmuir, 2017, 33, 10726-10735.

25 J. M. Zook, S. E. Long, D. Cleveland, C. L. A. Geronimo and R. I. MacCuspie, Anal. Bioanal. Chem., 2011, 401, 1993-2002.

26 K. Loza, J. Diendorf, C. Sengstock, L. Ruiz-Gonzalez, J. M. Gonzalez-Calbet, M. Vallet-Regi, M. Koller and M. Epple, J. Mater. Chem. B, 2014, 2, 1634-1643.

27 Z. Y. Wang, A. von dem Bussche, P. K. Kabadi, A. B. Kane and R. H. Hurt, ACS Nano, 2013, 7, 8715-8727.

28 A. M. Tavares, H. Louro, S. Antunes, S. Quarre, S. Simar, P. J. De Temmerman, E. Verleysen, J. Mast, K. A. Jensen, H. Norppa, F. Nesslany and M. J. Silva, Toxicol. in Vitro, 2014, 28, 60-69.

29 H. E. Pace, N. J. Rogers, C. Jarolimek, V. A. Coleman, C. P. Higgins and J. F. Ranville, Anal. Chem., 2011, 83, 9361-9369.

30 K. Rasmussen, J. Mast, P. J. de Temmerman, E. Verleysen, N. Wegeneers, F. van Steen, J. C. Pizzolon, L. de Temmerman, E. van Doren, K. A. Jensen, R. Birkedal, M. Levin, S. H. Nielsen, I. K. Koponen, P. A. Clausen, V. Kofored-Sørensen, Y. Kembouche, N. Thieriet, O. Spalla, C. Giuot, D. Rousset, O. Witschger, S. Bau, B. Bianchi, C. Motzkus, B. Shivachev, L. Dimowa, R. Nikolova, D. Nihtianova, M. Tarassov, O. Petrov, S. Bakardjieva, D. Gilliland, F. Pianella, G. Ceccone, V. Spampinato, G. Cotogno, P. Gibson, C. Gaillard and A. Mech, JRC Science and Policy Reports, 2014, http:// publications.jrc.ec.europa.eu/repository/handle/JRC86291.

31 M. Naiim, A. Boualem, C. Ferre, M. Jabloun, A. Jalocha and P. Ravier, Soft Matter, 2015, 11, 28-32.

32 P. A. Hassan and S. K. Kulshreshtha, J. Colloid Interface Sci., 2006, 300, 744-748.

33 R. D. Deegan, O. Bakajin, T. F. Dupont, G. Huber, S. R. Nagel and T. A. Witten, Nature, 1997, 389, 827-829.

34 P. J. De Temmerman, E. Van Doren, E. Verleysen, Y. Van der Stede, M. A. D. Francisco and J. Mast, J. Nanobiotechnol., 2012, 10, 24.

35 P. Muneesawang and C. Sirisathitkul, J. Nanomater., 2015, 2015, 8 .

36 R. J. Griffitt, A. Feswick, R. Weil, K. Hyndman, P. Carpinone, K. Powers, N. D. Denslow and D. S. Barber, Environ. Toxicol., 2011, 26, 541-551.

37 T. T. Morgan, H. S. Muddana, E. I. Altinoglu, S. M. Rouse, A. Tabakovic, T. Tabouillot, T. J. Russin, S. S. Shanmugavelandy, P. J. Butler, P. C. Eklund, J. K. Yun, M. Kester and J. H. Adair, Nano Lett., 2008, 8, 4108-4115.

38 G. Dordelmann, D. Kozlova, S. Karczewski, R. Lizio, S. Knauer and M. Epple, J. Mater. Chem. B, 2014, 2, 72507259.

39 S. Lee, X. Y. Bi, R. B. Reed, J. F. Ranville, P. Herckes and P. Westerhoff, Environ. Sci. Technol., 2014, 48, 10291-10300. 